\title{
Article
}

\section{Simulation of Shield Current in Automotive High Voltage Systems}

\author{
Jozsef Gabor Pazmany ${ }^{1, *}$, Denes Fodor ${ }^{2}$ and Bernard Bäker ${ }^{1}$ \\ 1 Institut für Automobiltechnik Dresden (IAD), 01062 Dresden, Germany; bernard.baeker@tudresden.de \\ 2 Faculty of Engineering, University of Pannonia, 8200 Veszprém, Hungary; fodor@almos.uni-pannon.hu \\ * Correspondence: pazmany.jozsef@gmail.com
}

Citation: Pazmany, J.G.; Fodor, D.; Baeker, B. Simulation of Shield Current in Automotive High Voltage System. World Electr. Veh. J. 2021, 12, 217. https://doi.org/10.3390/ wevj12040217

Academic Editor: Joeri Van Mierlo

Received: 31 August 2021

Accepted: 27 September 2021

Published: 3 November 2021

Publisher's Note: MDPI stays neutral with regard to jurisdictional claims in published maps and institutional affiliations.

Copyright: (c) 2021 by the authors. Licensee MDPI, Basel, Switzerland. This article is an open access article distributed under the terms and conditions of the Creative Commons Attribution (CC BY) license (https:// creativecommons.org/licenses/by/ $4.0 /)$.

\begin{abstract}
In automotive high voltage (HV) systems, the switching operation of a power electronic converter causes current and voltage ripple in the frequency range of [10 Hz-150 kHz]. Automotive system engineering provides requirements that define the behaviour of HV components in that frequency range. Shielded HV cables must stand induced current in the frequency range of the ripple. One of the relevant requirements is the maximal current stress of the shielding. Several individually shielded cables are used in automotive HV systems, and these shields influence differential mode disturbance currents, such as the ripple current from the traction inverter. In this work, we provide a model and an analysis of shielded cables integrated into an automotive HV system in relation to system-level design parameters. To fill the gaps of existing research, we focused on two questions: How do design parameters influence the shield current value in the frequency range of the current ripple in a vehicle, and how should a shield and connector system be designed with respect to shield currents over the life-time? We applied analytical and simulative solutions to these problems through a co-simulation approach on the architecture of a real vehicle. The presented approach extends existing research by integrating simulations and vehicle measurements to life-time prediction. Moreover, the proposed methods enable the replacement of the state-of-the-art constant 10 A requirement to a driver profile based predicted shield current requirement on individually shielded HV cables in battery electric vehicles (BEV).
\end{abstract}

Keywords: high voltage systems; automotive; shielded cables; shield current; voltage ripple

\section{Introduction}

In battery electric vehicles, the DC side HV cables of the traction inverter are often assembled with individual shields. A cost- and design-relevant property of the shield and its connector system is the current stress resistance. Data sheets of an HV cable and connector define only a constant root-mean-square (RMS) value for the shield current stress resistance, typically 10 A [1]. Due to the switching operation of power transistors in the traction inverter, differential mode (DM) ripple current is emitted into the HV system in the frequency range of $[10 \mathrm{~Hz}-150 \mathrm{kHz}][2,3]$. Ripple current can have an amplitude of up to $40 \%$ of the useful DC current [2]. In the frequency range of the ripple current, the dominant inductive coupling between the cable core and the shield induces shield current [4]. With the electrification of sport cars and heavy-duty vehicles, the nominal power of xEVs and the nominal DC current increase [5]; hence the specified shield current limit can be violated, yielding sporadic faults and accelerated ageing processes [6]. In this work, we provide a model and an analysis of shielded cables integrated into an automotive HV system in relation to system-level design parameters. The simulations aim to show the influence of design parameter changes to shield current. We also propose a new requirement for the current stress resistance of the shield and the connectors. The new requirement aims to predict the shield current stress over life-time of the vehicle. The results of this paper are validated with measurement data from real vehicles.

The HV power net of an electric vehicle can be designed with different shielding concepts. This work focuses on a vehicle with individually shielded HV cables, assembled 
between the traction inverter and the HV battery. Auxiliary loads with power of $\leq 10 \mathrm{~kW}$ are mostly connected to cables with a small radius $\left(4-6 \mathrm{~mm}^{2}\right)$ and common shielding. Individually shielded cables are usually used to connect the battery with the traction inverter usually individually shielded cables are used due to industrialisation advantages, but they can have both common mode and differential mode disturbances due to the inductive coupling of DM current. Numerous researchers have recently examined the modelling of the voltage ripple emission of automotive traction inverters [7-9]. Studies motivated by electromagnetic compatibility (EMC) covered the properties of shielded systems in automotive applications in the frequency range of $>150 \mathrm{kHz}$, such as $[6,10,11]$. Moreover, the impact of the ripple voltage on the passive components such as the DC-link capacitors and on the HV battery were scoped in several studies, such as in $[5,7,12,13]$. Voltage ripple issues are also covered by automotive standards, such as in [14]. Many researchers $[1,6,10,15-18]$ have examined the properties of shielding and shield current in automotive HV systems. They examined the AC cabling between the traction inverter and the electric machine, in the 3-phase AC system. If shielded cables are used, a part of the useful AC current occurs on the shielding due to inductive coupling, mostly in the frequency range of [0-1 kHz]. Section 5 [15] briefly defines the role of individual shielding in the DC side ripple current calculation, following [3]. However, existing research covers the modelling of the voltage ripple emission of a traction inverter, the ripple caused faults and accelerated ageing of some components in the HV system, and the modelling of an individually shielded cable, the existing literature poorly covers the behaviour of a shielded cable in real vehicular environment. Reference [15] covers the basic modelling of an individually shielded cable in the HV system, but without the assessment of requirements on the cable or of the behaviour in drive-cycles. The standardised method on shield current stress provided in [14] does not cover the voltage ripple modelling and the lifetime shield current stress. Moreover, parameter optimisation in HV systems with respect to voltage ripple in the literature focuses on capacitor sizing [13], but also the design parameter optimisation of the shielding system with respect to voltage ripple behaviour is a promising direction for avoiding accelerated ageing or sporadic faults.

Our objective in this research is to combine the knowledge about voltage ripple and cable modelling and system-level knowledge to define the current stress resistance requirement for shields, and grounding resistors and to examine the influence of shielding parameters on HV system modelling in the frequency range of [10 Hz-150 kHz]. We conducted a detailed system analysis and a simulation in a real vehicular environment with real system parameters to answer the research questions. We also analysed the system gradients with respect to design parameters, such as cable length, resistances, and capacitor sizes.

In designing shield connectors, the HV system specifications provided state that the maximal allowable RMS current, measurable in the shielding of HV cables, is typically $10 \mathrm{~A}$. Meanwhile, in the automotive HV system specifications, the maximum shield grounding resistance is $10 \mathrm{~m} \Omega$ [13]. The grounding resistance determines the functional robustness of the connector against current stress. In recent measurements, high currents have been observed on individually shielded cables between the inverter and the battery. The spectral analysis of these currents has shown that the origin of these DM disturbances is the switching operation of the traction inverter. In this work, we analysed the physical phenomena of the shield current. Based on the analysis, we defined the maximal current levels emitted by the inverter in the frequency domain to secure maximal RMS current on the shield connectors. In addition, we examined the trade-off between reducing current ripple in the HV cables and preparing the shielding for higher RMS current stress. We also defined the properties and calculation of the shield current in the frequency range of $[10 \mathrm{~Hz}-150 \mathrm{kHz}]$, followed by the extrapolation of drive cycles and life-time current stress approximations. For life-time approximation, a new definition of shield current stress requirement was provided. The modelling built on the results of the latest modelling research on automotive HV systems, particularly ripple voltage properties $[2,7,13]$. In this paper, we show 
the results of high-fidelity shield modelling integrated into a real vehicular environment, with a focus on modelling error and requirement definition on the shielding's current stress resistance. According to [2], the analytical modelling approach for system-level ripple simulations contains different errors. The individually shielded cables contribute to the modelling error, hence we propose a new approach to estimating this uncertainty and a co-simulation to enhance the fidelity of shield current simulations.

From a system integration perspective, the modelling of shield currents is essential in designing a shield and connector system. The proposed method aims to predict shield currents over realistic drive-cycles and use case near life-time approximations.

This work is structured as follows: Section 2 presents the cable, system and drive cycle modelling approach. Section 3 shows the results of the analysis for shield current calculation and modelling error determination, while in Section 4 the extrapolation of drive-cycles is discussed. Section 5 focuses on simulation and measurement results and our suggestions for requirement definitions.

\section{Materials and Methods: Modelling Shield Current}

To provide high-fidelity shield current modelling the cable, the HV system and the disturbance source were analysed in the frequency range of [10 Hz-150 kHz]. This section outlines all modelling aspects and assumptions. The defined models were used in the simulation method using a co-simulation of MATLAB and a finite element method (FEM) solver, in this case finite element magnetics (FEMM).

\subsection{Cable Model}

Figure 1 shows the cross-section of the $50 \mathrm{~mm}^{2} \mathrm{Cu} \mathrm{HV}$ cable, which is assembled between the traction inverter and the battery. The FEMM model of the shielded cable contains the cable core model and the shield and calculates the skin effect in the cable core. To create the cable model, the following assumption was made;

Assumption 1. The capacitive coupling between the core and the shield should be neglected in the frequency range of [10 Hz-150 kHz]. Inductive coupling is dominant between the core and the shield in this frequency range. This assumption is proven by FEM simulations.

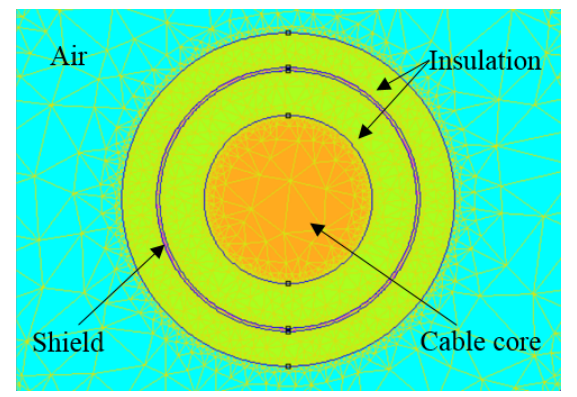

Figure 1. FEMM model of a single $50 \mathrm{~mm}^{2}$ copper $\mathrm{HV}$ traction cable.

The shield current model contains three sub-models. The simplified system model, containing all three sub-models is illustrated in Figure 2. A detailed ripple source model, (i.e., an inverter model) is analogous to the one described in [15]. As shown in Section 5, the adjusted impedance of the HV system is yet to be modelled. Additionally, a model of the shielded cable and its connection to the vehicular ground should be modelled. We assume the impedance of the HV system and the inverter model as given. Further discussion on the ripple source and HV system modelling can be found in [3,4,7], respectively. The analysis assumes an $800 \mathrm{~V}$ system with one traction inverter, one battery, and two parallel connected auxiliary loads, where the traction inverter operates with space vector modulation (SVM).

Shield current stress calculation requires a high-fidelity cable model in the frequency range of the current ripple following [1]. The modelling approach used considers two 
variable design parameters, cable geometry and ground resistance, encompassing grounding resistance $\left(R_{u e}\right)$ and vehicle ground resistance $\left(R_{G N D}\right)$. System gradients with respect to these design parameters were obtained using algebraic steps. In the given ripple source, the shield current analysis follows Kirchhoff's law for current equations at marked point 1 in Figure 3, Figure 4 shows the examined currents. The system parameter determined the current over the DC-link capacitor $\left(C_{x}\right)$ and the current over the HV cable. Figure 5 is the model of a shielded cable in the frequency range of [10 Hz-150 kHz]. We conducted sensitivity analysis to examine the effect of design guidelines and feasible parameter changes. From the circuit analysis of the cable model it was found that $I_{- \text {Ripple }, \text { Shield }}=\Phi\left(I_{- \text {Ripple, }, \text { able }}, k, R_{\text {contact }}, L_{S}, L_{C}\right)$.

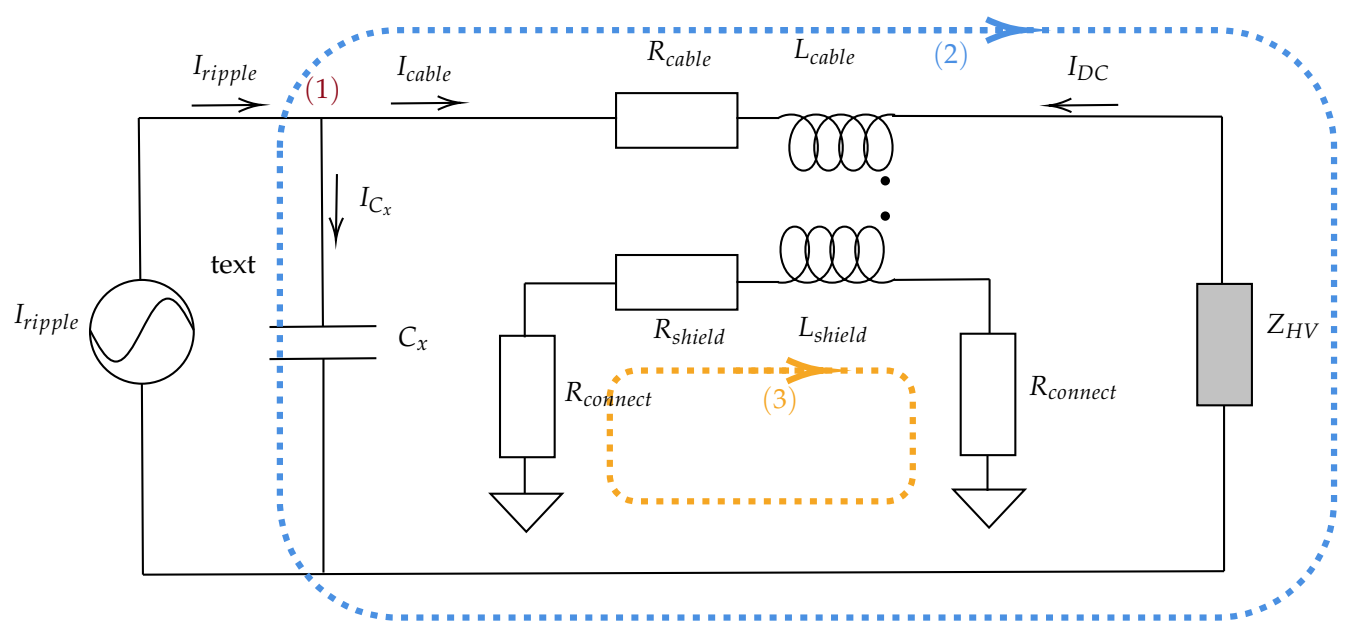

Figure 2. Simplified equivalent circuit representation of the examined system, with an individually shielded HV cable.

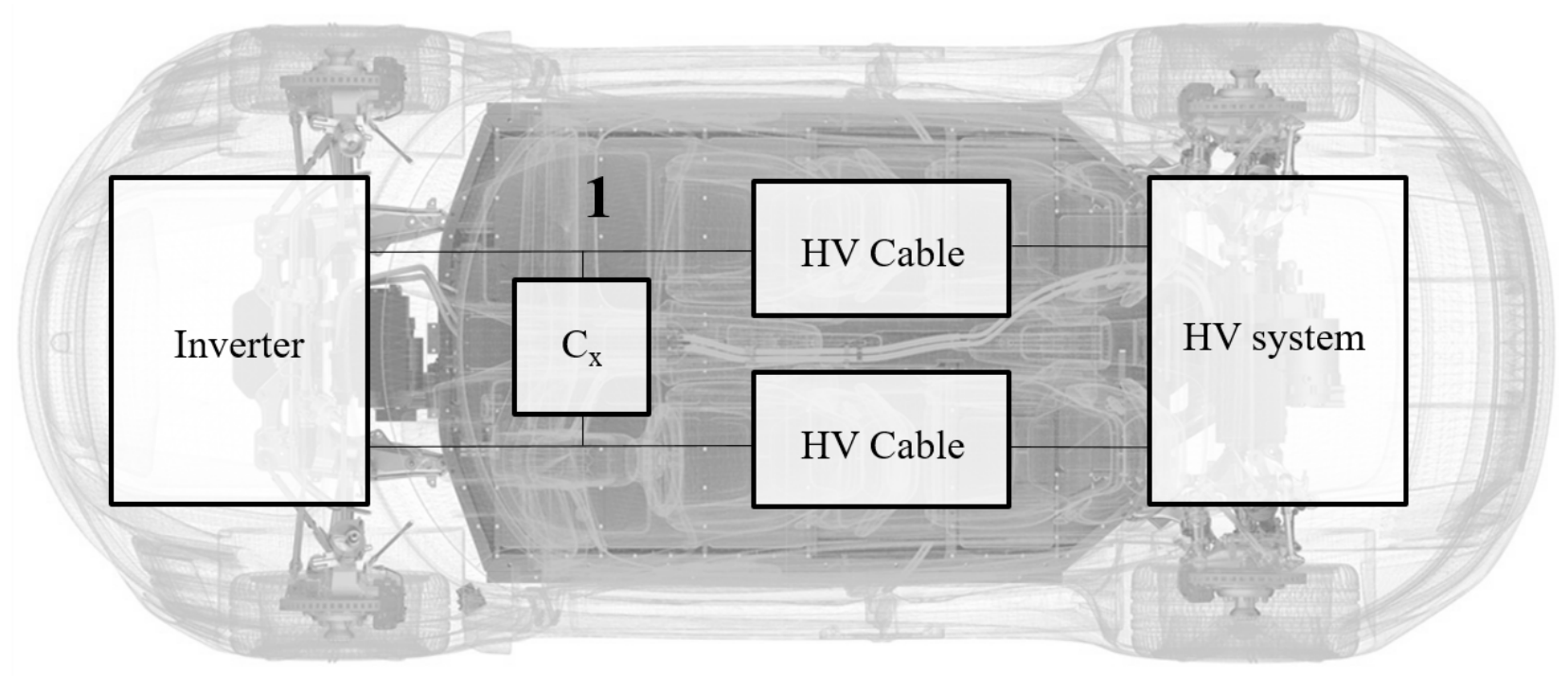

Figure 3. Subsystems for the examination of the shield currents. The inverter and current emission model is discussed in Section 6. The system impedance model is discussed in [7,19]. The DC-link capacitor is modelled as an RC element [13]. 


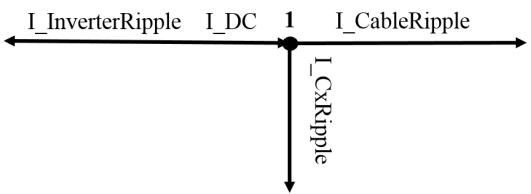

Figure 4. System relevant currents at the marked point (1) in Figure 3, that are the bases for the Kirchhoff's analysis.

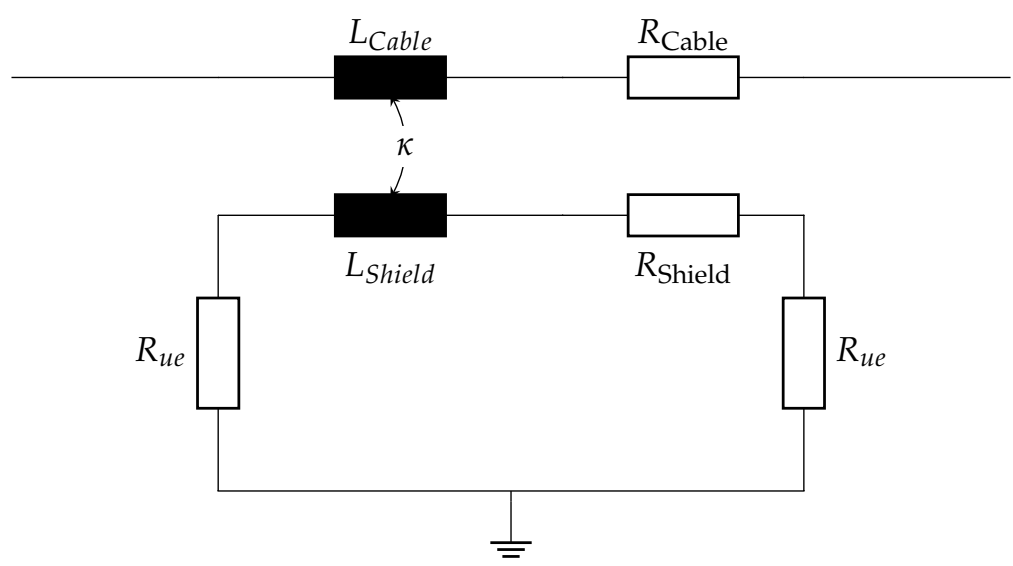

Figure 5. Modelling of one individually shielded HV cable where both ends of the shielding are connected to the vehicle ground (GND). The resistor $R_{u e}$ represents the connecting resistance, which is a design value in the system requirement sheet. $\kappa$ is the coupling factor between the shield and the cable core. The resistance and inductivity of the cables $\left(L_{\text {cable }}\right.$ and $\left.R_{\text {cable }}\right)$ are discussed in Figure 6.

For the simulations and measurements of DM shield current, a $50 \mathrm{~mm}^{2}$ coppera cable around $1 \mathrm{~m}$ in length-was examined [20]. The simulation always assumes a straight cable, with $d>>r$, where $r$ is the cable radius and $d$ is the distance between the $H V+$ and $H V-$ cables.

To examine the contribution of ripple current to shield current, a high-fidelity cable model was developed in the frequency range of the inverter ripple, that is, [10 Hz-150 kHz]. Therefore the following assumptions were made:

Assumption 2. The cables are short $l<<\lambda_{150 \mathrm{kHz}}$.

Assumption 3. The parasitic capacitance between the cable core and the shield should be neglected.

Assumption 4. $H V+$ and $H V-$ cables are parallel and straight.

Assumption 5. The shield is thick such that skin effect can be neglected in the shield model.

Assumption 6. Ground impedance is idealised to a concentrated resistive element.

Connectors, such as the standard HVA280 in [21], were modelled as serial $R L$ elements without thermal or transient parameter changes.

The simulation was based on a system model developed with MATLAB tools and was co-simulated with an embedded FEMM cable model. MATLAB scripts provided the parametrisation and the solution of Kirchhoff equations and the inverter ripple emission calculations. FEMM simulations established the cable models. Simscape models provided accusal circuit simulations.

\subsection{System Model}

The HV system of a BEV is a power-electronics-interfaced DC power system. In this work, we assumed an $800 \mathrm{~V}$ system with a $240 \mathrm{~kW}$ traction inverter. The main ripple 
current source is the traction inverter. According to [2,10], the inverter should be modelled in this frequency range with its Northron equivalent circuit where the inner impedance of the source contains the DC-link capacitor. Notably, in this work we only considered one traction inverter and neglected the ripple emitted by auxiliary loads.

The scope is the cabling between the inverter and the HV distributor. This cable has symmetrical connector systems in both ends of it. The system impedance was based on measurements fitted for equivalent circuit representation, following [19,22].

The cable modelling contains the frequency dependency of the inductance and the resistance of the cable core-following the calculated results presented in Figure 6-which corresponds to [23].
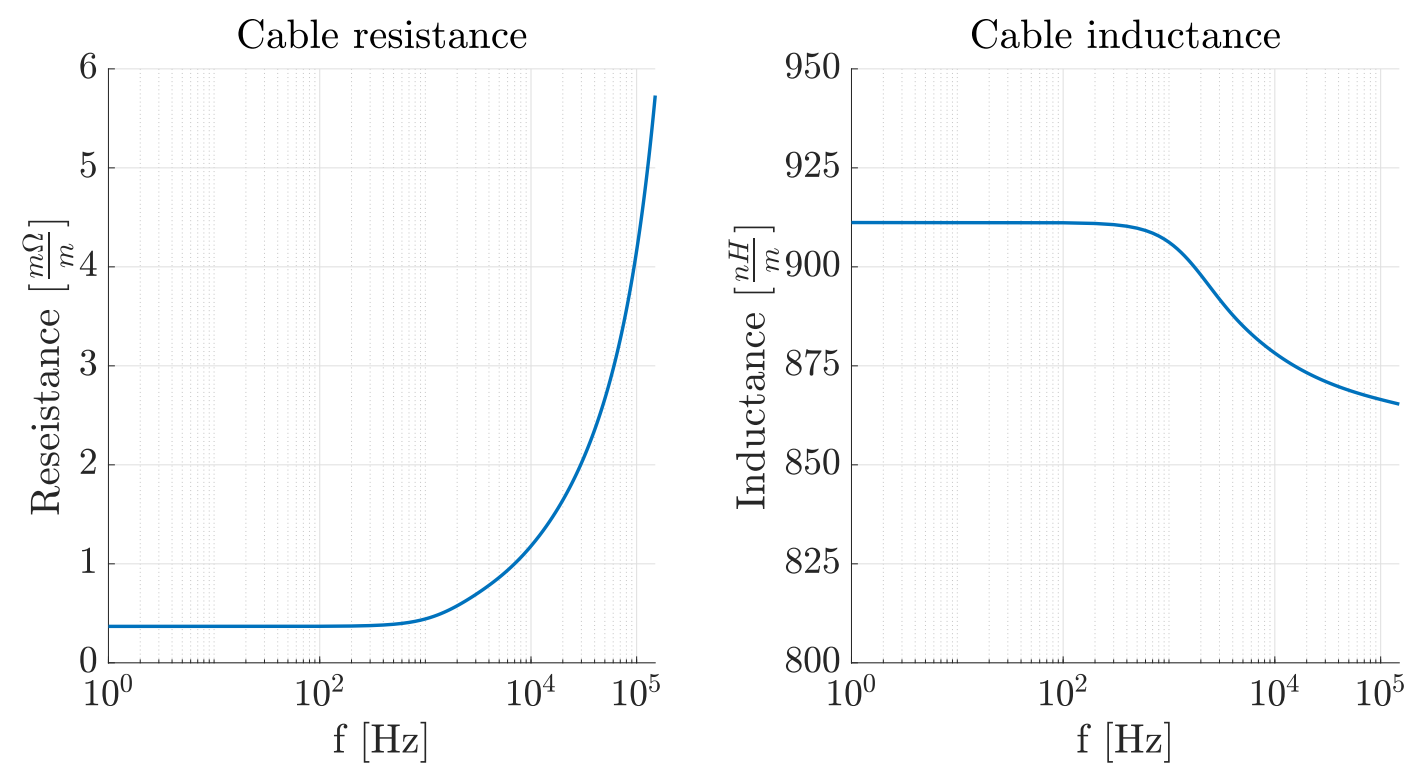

Figure 6. Inductance and resistance of a $50 \mathrm{~mm}^{2}$ copper cable for EV usage in the frequency range of [10 Hz-150 kHz]; the results are provided using FEMM simulation. Notably, this work focuses on the shield current in the frequency range of $[10 \mathrm{~Hz}-150 \mathrm{kHz}]$. The further simulations use the provided inductance and resistance values for the HV cables in the specified frequency range.

\subsection{Analytical Model}

The real vehicular system model contains three subsystem models. The traction inverter model to reproduce the ripple current source in the vehicle followed [1]. Input for the drive-train configuration in the inverter model included the actual mechanical torque, machine speed, modulation index, and DC voltage. Using the Bessel approximation, we calculated real ripple current with amplitude, phase, and corresponding frequency $I_{i}$, using the ripple spectrum that contains only finite discrete frequencies where the ripple amplitude is $\geq \epsilon$. The inverter model also contains the DC-link capacitor model.

A system impedance model reproduces the effect of the other components in the HV system such as the battery or an auxiliary HV component (e.g., DCDC converter or HV heater), following the results of [16]. The HV system impedance was taken into account in the calculation as the concentrated DM parameter, $Z_{H V}$.

A detailed cable model was produced to calculate the ripple current transfer between cable and core. The detailed model contains the RL model of the cable and the mutual capacitance and inductance of cable and shield.

The system model in Figure 2 shows three Kirchhoff equations (marked with 1, 2, 3) that constitute the core of further analytical examinations.

$$
I_{i}=I_{c}+I_{l}
$$




$$
\begin{gathered}
0=I_{l}\left(R_{l}+Z_{\mathrm{HV}}+L_{l} w 1 \mathrm{i}\right)+\frac{I_{c} 1 \mathrm{i}}{C_{x} w}+I_{S} M w 1 \mathrm{i} \\
0=I_{s}\left(R_{\text {sum }}+L_{s} w 1 \mathrm{i}\right)+I_{l} M w 1 \mathrm{i}
\end{gathered}
$$

With measured system parameters and some algebraical steps, we solved the shield current $\left(I_{s}\right)$, cable core current $\left(I_{l}\right)$ and the DC-link capacitor current $\left(I_{C}\right)$ in regard to system parameters.

Further examinations assumed a real drive situation, with passive auxiliary loads, so the DC current could flow from the battery to the inverter, meaning driving, or in the other direction, meaning braking [7]. Ripple current flowed from the inverter towards the HV system, suggesting that the inverter is the ripple source, and the HV system is the ripple sink. The analytical model obtained the coupling factor between the cable core and the shield from the FEM simulations of corresponding cables.

\subsection{Inverter Ripple Current Model}

The inverter ripple current calculation followed the Bessel approximation of the emitted ripple current of an inverter, as shown in [21]. Inverter ripple emission was modelled as a current source with a complex frequency spectrum that depended on the actual switching frequency, operation point, and modulation strategy [2].

\section{Analysis}

In this section, we present analytical calculations of parameter dependencies between shield and cable current. The bases for the analyses were calculations of the transfer function from the inverter current to the shield current and to the cable current. The analysis confirmed the influence of the shield parameters on the ripple current in the inner conductor. We also examined the effect of system parameters on the shield current. A sensitivity analysis was conducted to gauge the effect of design parameters on current properties.

The transfer function from inverter ripple current to shield current suggested a bandpass filter-like system. The exemplary HV system impedance had two parallel coupled LC DC-link filters with a high $Q$ factor. Figure 7 shows that resonance points also cause local maxima in the transfer function. The simulation results are presented in Figure 7 with three different values for the grounding resistance. The simulation results showed the damping effect of the connecting resistance of the shield.

Corollary 1. The shield current in relation to system parameters can be written in closed mathematical form. The shield current function has a negative gradient against contact resistance, so $\frac{\partial I_{\text {Shield }}}{\partial R_{\text {ue }}}<0$. In practical terms, the lower connector resistance means higher shield current.

The transfer function from the inverter ripple current to the cable core current showed similarities with the transfer function of a low-pass filter, which can be explained by the DC-link capacitor of the inverter. The two resonance points can be observed due to the input filter of the HV auxiliary loads. Figure 7 presents the exemplary transfer function with two HV loads and a real DC-link capacitor, with three different contact resistances. The influence of the design parameters on the filter performance of the DC-link capacitor has been studied; hence the following properties were simulated.

Corollary 2. For every system configuration and $R_{u e} 0$ exists a frequency $f_{0}$ such that:

$$
\begin{gathered}
\text { If } f<f_{0} \text { then } \frac{\partial I_{\text {Cable }}}{\partial R_{u e}}>0 \\
\text { Else } \frac{\partial I_{\text {Cable }}}{\partial R_{u e}} \leq 0 .
\end{gathered}
$$

There exists a frequency, below which the shield behaves as a reduction conductor, and above which the shield amplifies the measurable current in the conductor core. 


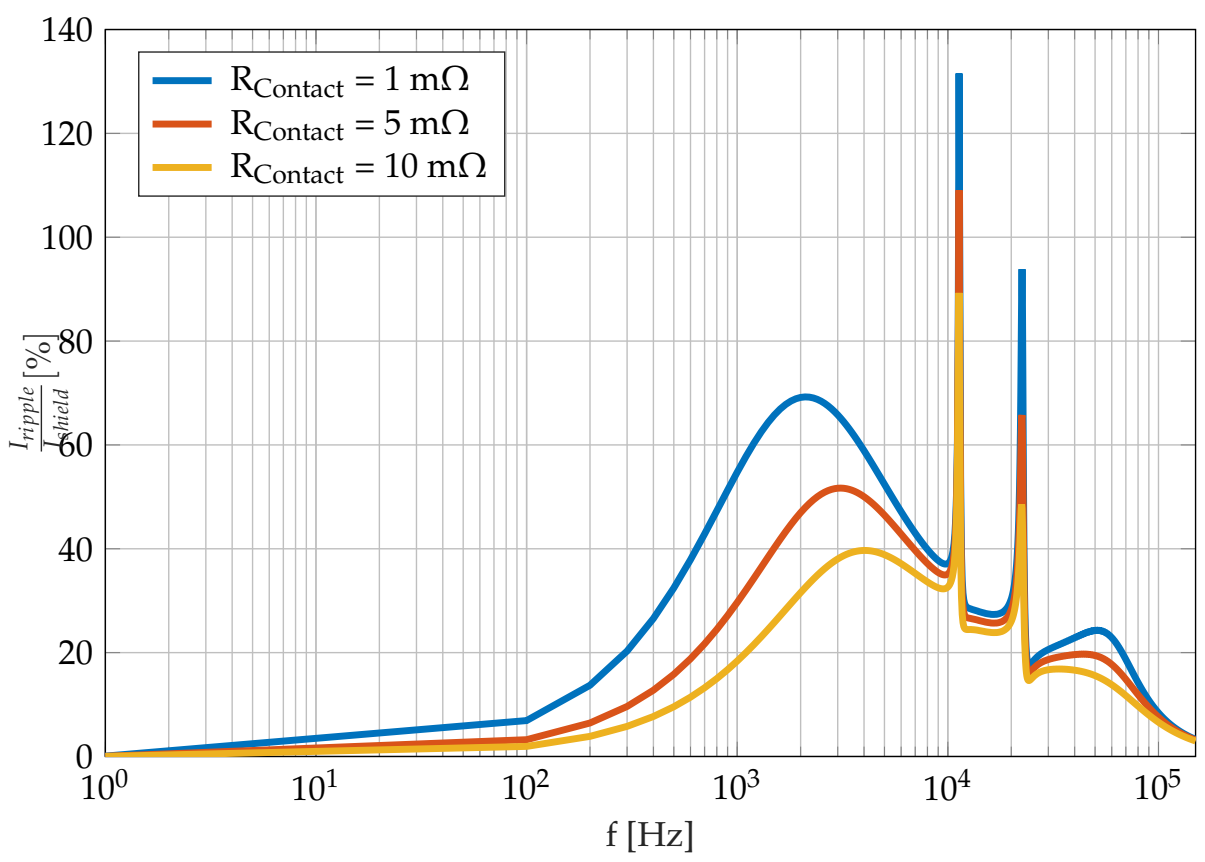

Figure 7. Simulated proportion of shield and inverter currents in the function of frequency with three different contact resistance values. With low shield resistance at the resonance frequency of the HV system the individual shield can amplify the inverter ripple current.

\subsection{Parameter Dependencies of Shield Current}

To examine the effect of the design parameters and observe possibilities of the systemlevel parameter tuning, the transfer function between the inverter ripple current and the shield current was derived. The transfer function between the inverter ripple current and the shield current was also derived. The simulated transfer function is shown in Figure 8. Calculations of the three different parameters showed significant changes in behaviour at the resonance frequencies of the auxiliary HV loads. Damping properties also changed in the grounding resistor parameter.

Figure 9 presents the calculated transfer function between the ripple current in the inverter and in the cable core. The effect of parameter changes was similar to that of the transfer function presented in Figure 8.

Since the parameters in the transfer functions were not linearly independent, the simulation of $\frac{I_{\text {CableRipple }}}{I_{\text {InverterRipple }}}$ was conducted to visualise their effect on the ripple current. Figure 10 shows The simulation results, indicating switching frequencies in the traction inverter. This suggest a resonance phenomena (e.g., at $11 \mathrm{kHz}$ ) tuning other system parameters and shield grounding resistor $R_{u e}$ damping the resonance current in the system. Moreover, with the tuning of the inverter switching frequency and the shield grounding resistance the shield current can be minimised, or the dumping of the shield on cable inductance can be maximised. 


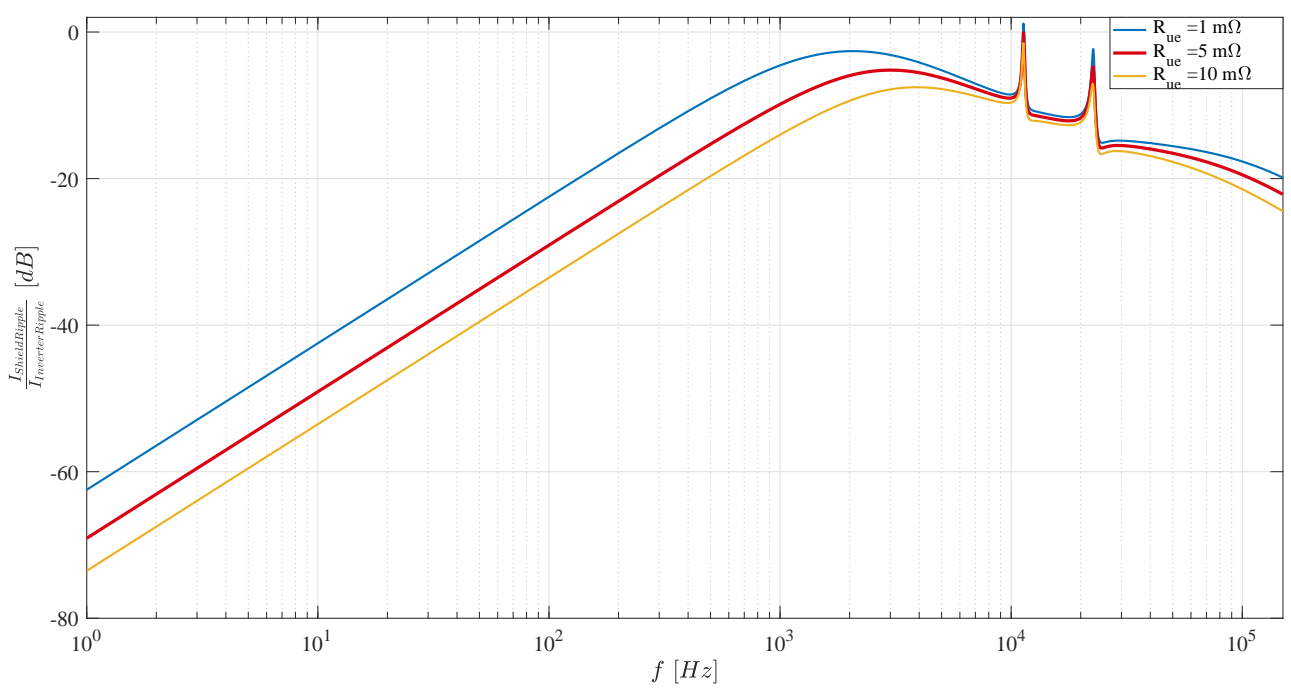

Figure 8. Proportion of shield and inverter ripple currents in the frequency function with three different contact resistance.

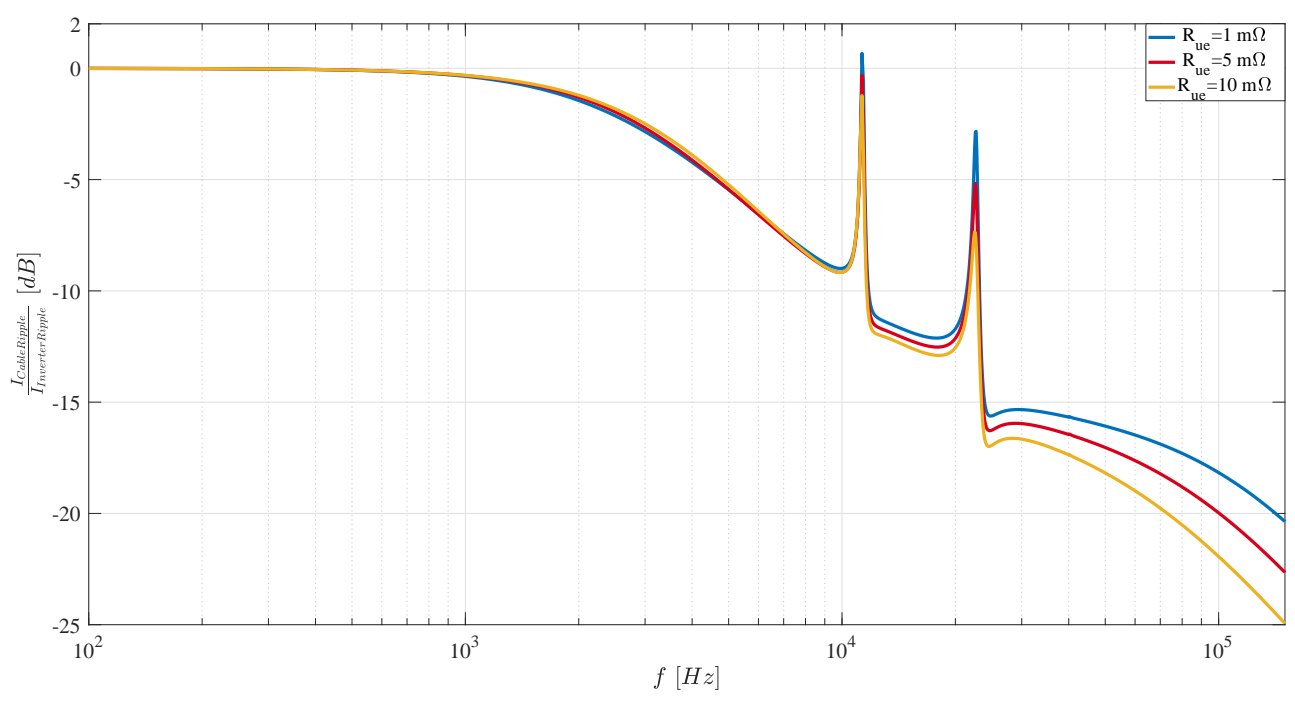

Figure 9. Proportion of cable core ripple and inverter ripple currents in the function of frequency with three different contact resistance.

\subsection{Effect of Shielding on System-Level Ripple Modelling}

Figure 11 shows the qualitative impact of the design parameter changes on the transfer function from inverter ripple current to shield current. The results show the modification of the band-pass properties of the shielded system, the higher resistance values cause better damping, the modification of the cable length also modifies the shield currents. Table 1 summarizes the qualitative impact of design parameters to transfer function from inverter ripple to shield current, the table also provides information on the possibilities of damping undesired shield current related phenomena in the HV system. 


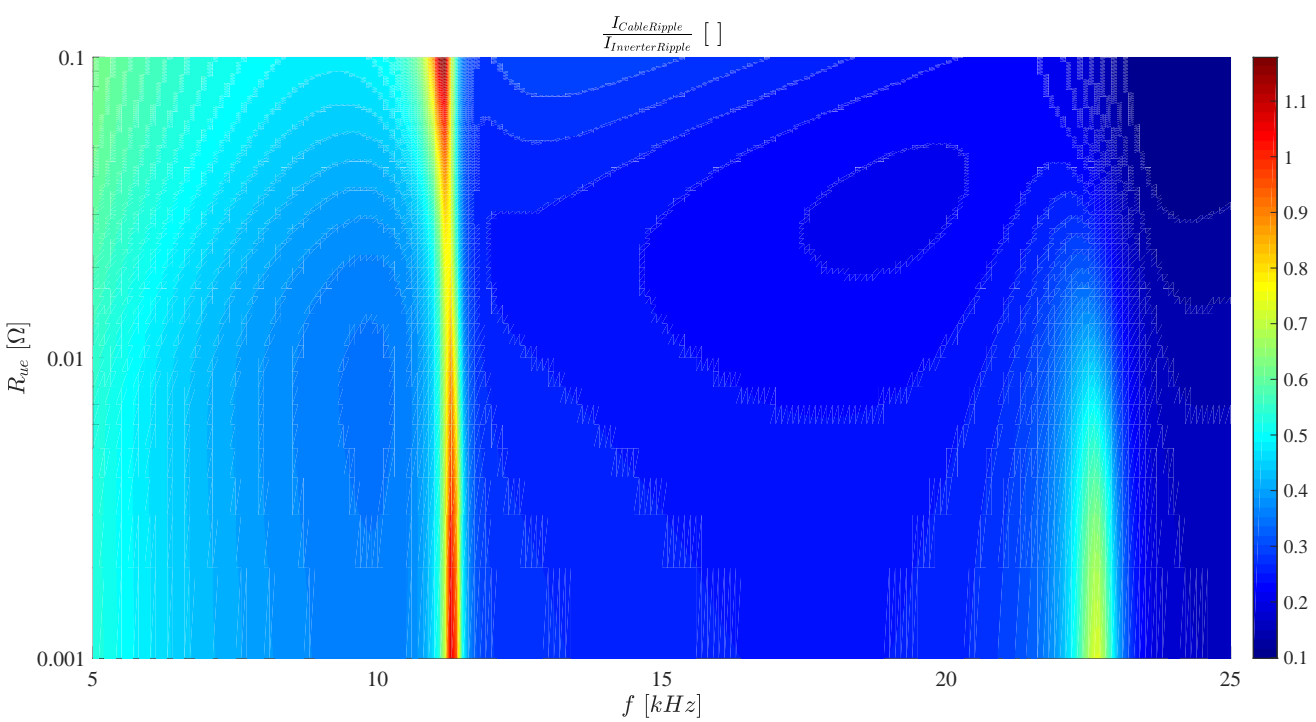

Figure 10. Simulated mapping of proportion of cable and inverter currents in the function of frequency and the shield grounding resistance.

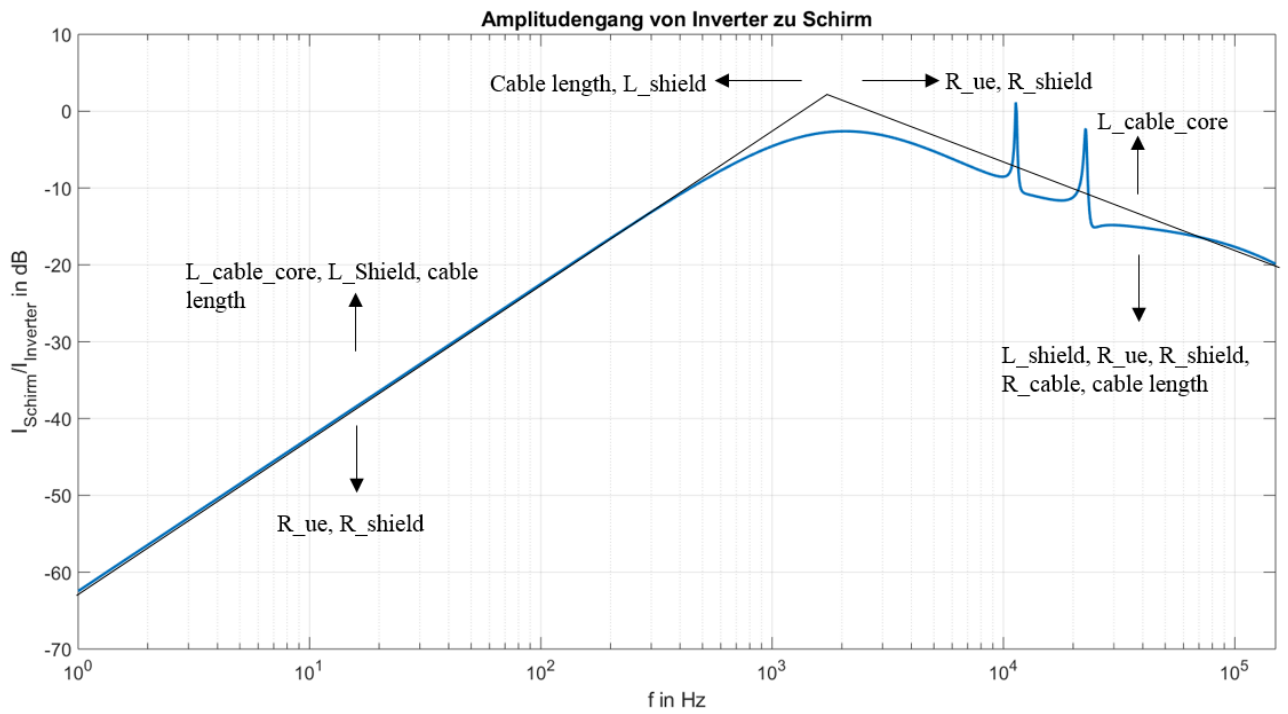

Figure 11. Qualitative effect of parameter changes on the transfer function from inverter ripple current to shield current.

In the HV-system, the effect of an individually shielded cable on conducted DM disturbances in the low frequency range is caused by mutual inductance in the shield and the cable core. The individual shield slightly shifted the resonance points of the system and the current distribution between the DC-link capacitor of the inverter and the HV-system. The resonance point shift is critical in terms of maximal ripple current on side loads. As an analysis example, an auxiliary load is assumed with a DC-link capacitor $C_{x}$, a DM choke $L_{d m}$, cable inductance $L_{l}$ and shield inductance $L_{s}$. The resistance of the cable, connector and equivalent series resistor (ESR) of the capacitor is summarized in $R_{s y s}$. The effect of shield parameters on the resonance shift is obtained analytically in the following equations. In the formula below, $\omega$ is the resonance frequency for the shielded system, and $\omega_{n}$ is in the unshielded system.

$$
\omega=\frac{1}{\sqrt{C_{x}\left(L_{d m}+2 L_{l}+2 k \sqrt{L_{l} L_{s}}\right)}}
$$




$$
\begin{gathered}
\omega_{n}=\frac{1}{\sqrt{C_{x}\left(L_{d m}+2 L_{l}\right)}} \\
\frac{\partial \omega}{\partial L_{s}}=-\frac{C_{x} L_{l} k}{2\left(C_{x}\left(L_{d m}+2 L_{l}+2 k \sqrt{L_{l} L_{s}}\right)\right)^{3 / 2} \sqrt{L_{l} L_{s}}} \\
\frac{\partial \omega}{\partial k}=-\frac{C_{x} \sqrt{L_{l} L_{s}}}{\left(C_{x}\left(L_{d m}+2 L_{l}+2 k \sqrt{L_{l} L_{s}}\right)\right)^{3 / 2}} .
\end{gathered}
$$

Table 1. Qualitative effect of design parameter changes on shield the current. The analysis is based on the results shown in Figure 11.

\begin{tabular}{ccc}
\hline Parameter & Change $(\nearrow \mid \searrow)$ & Effect \\
\hline$R_{u e}$ & $\nearrow$ & $\begin{array}{c}\text { higher resonance frequency, } \\
\text { steeper low-high pass properties }\end{array}$ \\
\hline$R_{u e}$ & $\begin{array}{c}\text { lower resonance frequency, } \\
\text { smoother low-high pass properties }\end{array}$ \\
\hline$R_{\text {shield }}$ & $\nearrow$ & $\begin{array}{c}\text { higher resonance frequency, } \\
\text { steeper low-high pass properties }\end{array}$ \\
\hline$R_{\text {shield }}$ & $\searrow$ & $\begin{array}{c}\text { lower resonance frequency, } \\
\text { smoother low-high pass properties }\end{array}$ \\
\hline Cable length & $\nearrow$ & $\begin{array}{c}\text { lower resonance frequency, } \\
\text { smoother low-high pass properties }\end{array}$ \\
\hline Cable length & $\searrow$ & $\begin{array}{c}\text { higher resonance frequency, } \\
\text { steeper low-high pass properties }\end{array}$ \\
\hline$L_{\text {cable_core }}$ & $\nearrow$ & $\begin{array}{c}\text { lower resonance frequency, } \\
\text { smoother low-high pass properties }\end{array}$ \\
\hline$L_{\text {cable_core }}$ & $\searrow$ & $\begin{array}{c}\text { higher resonance frequency, } \\
\text { steeper low-high pass properties }\end{array}$ \\
\hline$L_{\text {shield }}$ & $\nearrow$ & $\begin{array}{c}\text { lower resonance frequency, } \\
\text { smoother low-high pass properties }\end{array}$ \\
\hline$L_{\text {shield }}$ & $\begin{array}{c}\text { higher resonance frequency, } \\
\text { steeper low-high pass properties }\end{array}$ \\
\hline
\end{tabular}

Figure 12 shows the numerical results of the sensitivity analysis with respect to the coupling factor. The effect of shielding on the function of cable inductance was calculated as follows:

$$
\begin{array}{r}
\frac{\partial \Delta \omega}{\partial L_{l}}=\frac{C_{x}\left(\frac{L_{s} k}{\sqrt{L_{l} L_{s}}}+2\right)}{2\left(C_{x}\left(L_{d m}+2 L_{l}+2 k \sqrt{L_{l} L_{s}}\right)\right)^{3 / 2}}- \\
-\frac{C_{x}}{\left(C_{x}\left(L_{d m}+2 L_{l}\right)\right)^{3 / 2}}
\end{array}
$$

where $\Delta \omega=\omega-\omega_{n}$. 

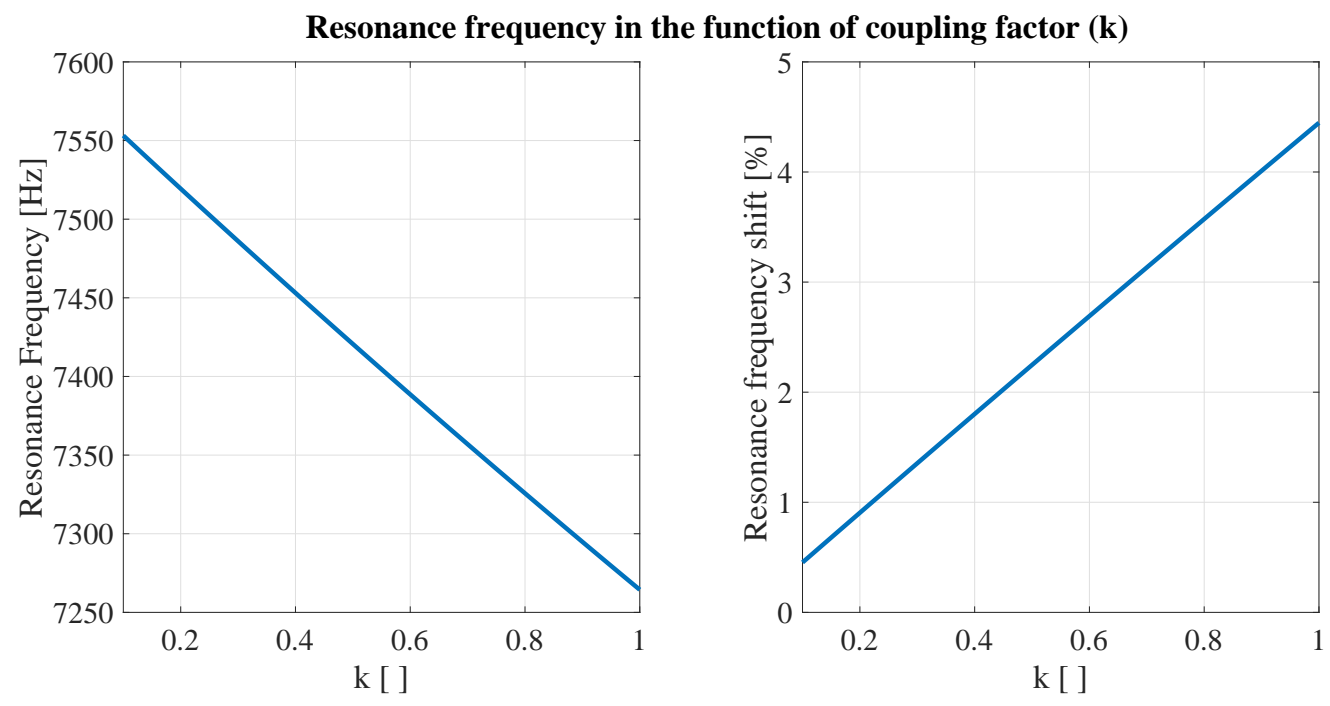

Figure 12. Impact of coupling factor $(\kappa)$ on the resonance frequency in an exemplary HV system.

\section{Shield Currents over Drive-Cycles}

In this section, we aim to predict the shield current in a real drive cycle, to extend current stress requirements for shields and connector systems. Actual specifications and data sheets included a constant RMS current stress. Measurements (Section 5.3) revealed that in some drive situations the shield current can be higher than the specified 10 A RMS. The thermal and ageing effect simulation of shield current on a connector system requires a predicted current profile as input.

In a real vehicular environment, the examination of the shield current considers parameter uncertainties, such as the shield contact resistance being temperature dependent or the spectrum of the inverter ripple current depending on the state of the electric motor [2].

After setting up the drive-train, system impedance, and cable model, the drive-cycles were defined. During a drive cycle, electric machine speed, torque, and DC voltage must be measured. With these input parameters, the ripple emission of the traction inverter was simulated, and shield current was calculated in every discrete measurement point. Simulation outputs were shield current pulses with their frequency spectrum and amplitude, and length in the time domain. We examined two different drive cycles of a real electric vehicle. A Worldwide Harmonised Light Vehicle Test Procedure (WLTP) standardised and a sporty driver profile. Figures 13 and 14 presents the simulated RMS current stress on the shield contact resistor in the two different drive-cycles.

Figure 13 shows the DC current and the RMS values of the ripple emission of the traction inverter as well as the cable core ripple current and the shield current. From these results we can determine the worst-case shield current pulses and a current profile for the thermal simulations. For the system design, we obtained the length of a high shield current period from the dataset.

Figure 14 visualises the comparison of the two driver profiles. Showing the effect of driver profile and the percentage of the share of time when a shield current appears larger than a specified level. With these results, we can validate a new requirement level, as they indicate the frequency of limit violations, as a percentage. These results also helped us to define a shield current stress level extended with the pulse length in the time domain. 


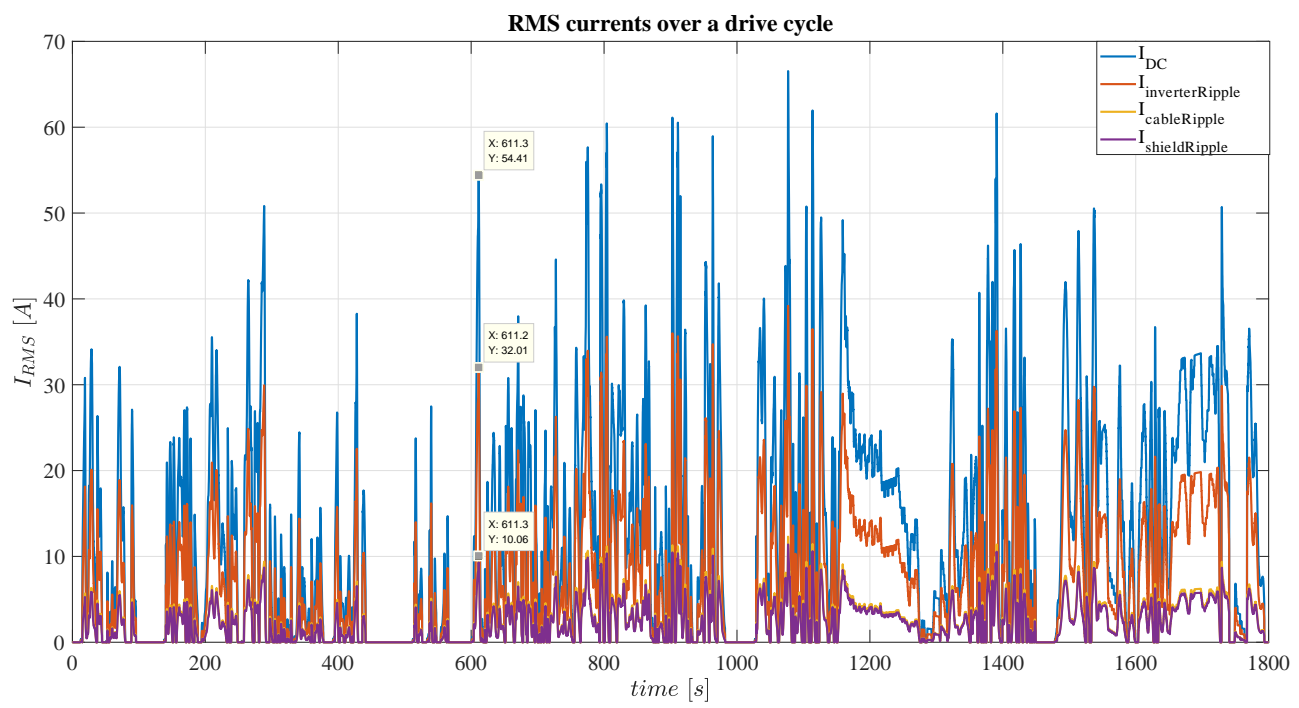

Figure 13. Simulated current levels of HV system currents over a WLTP-WLTC Class3 drive cycle, where the actual state of the electric drive-train and the DC voltage is based on real vehicle measurements. Simulations showed the presented current levels.

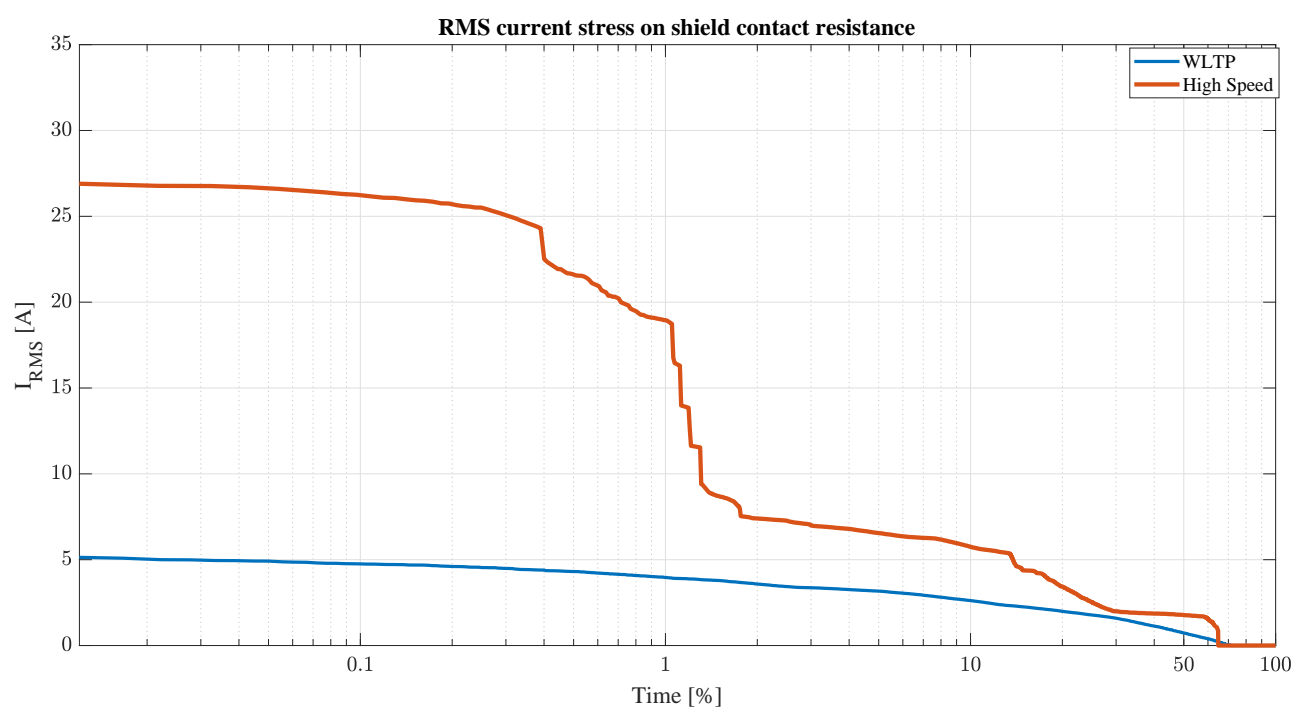

Figure 14. Simulation results of RMS current stress on shield contact resistors $R_{u e}=5 \mathrm{~m} \Omega$ in two different drive cycles. The results estimate the frequency of limit violations in different driving profiles.

\section{Result Discussion and New Design Guidelines for the Shielding of HV Cables}

In this section, we propose a method to predict current stress on the shield and connectors in BEV applications. The method is designed such that it can be applied in the early phase of vehicle development, using the inverter data sheet and the specified HV system topology. With this method, vehicle developers can predict shield currents in drive cycles and validate the usability of standard or custom shields and connectors for the vehicle life-time. The designed shield current profile can serve as an input for the thermal simulation of shields. We propose an estimated shield current profile for vehicle concepts. Accurate prediction method requires prior knowledge about the inverter, the HV system, and the drive cycles. The predicted current profile enables a lifetime prediction of shield grounding resistors.

We suggest conducting the shield current analysis during the vehicle concept design phase because shield current stress can influence the selection and type connector geometry and material. 


\subsection{Drive-Cycle Modelling}

Current stress on a shield or on a contact resistance depends on the actual state of the drive-train. Reality near drive situations and driver profiles are modelled with standard drive-cycles like the WLTP - WLTC Class3 cycle or NEDZ [24], which are also used for the homologation of the vehicle. In this research, we assume that the standard drive-cycles correspond to the behaviour of a real driver. For the simulations, the inputs a measured were a WLTP and a sporty drive cycle with aggressive acceleration and braking manoeuvres to model a worst-case scenario.

In the real drive situation the actual torque and speed of the electric machine and the $\mathrm{HV}$ voltage were measured over a drive-cycle with synchronised data acquisition equipment. For the simulations, we generated an input data set from the measurement results, which consisted of actual electric motor speed, torque, and HV voltage with a sampling frequency of $1 \mathrm{kHz}$. Simulation results of the ripple current stress on a shield provided the input for thermal simulations.

\subsection{Simulation of Real Drive-Cycles}

The high-level algorithm of the shield current simulation is presented in Figure 15. This algorithm ensured satisfactory shield current predictions for the system engineering. To conduct the simulation, we first measured different driver profiles with $1 \mathrm{kHz}$ sampling in an existing BEV. We then fed the shield current simulation with the measurement data from the battery and electric drives. Afterwards, the current ripple and the shield current for the two drive cycles was to be calculated and a profile was calculated with the frequency and length of shield current pulses. We propose using such a profile for the current stress resistance requirement of the shield.

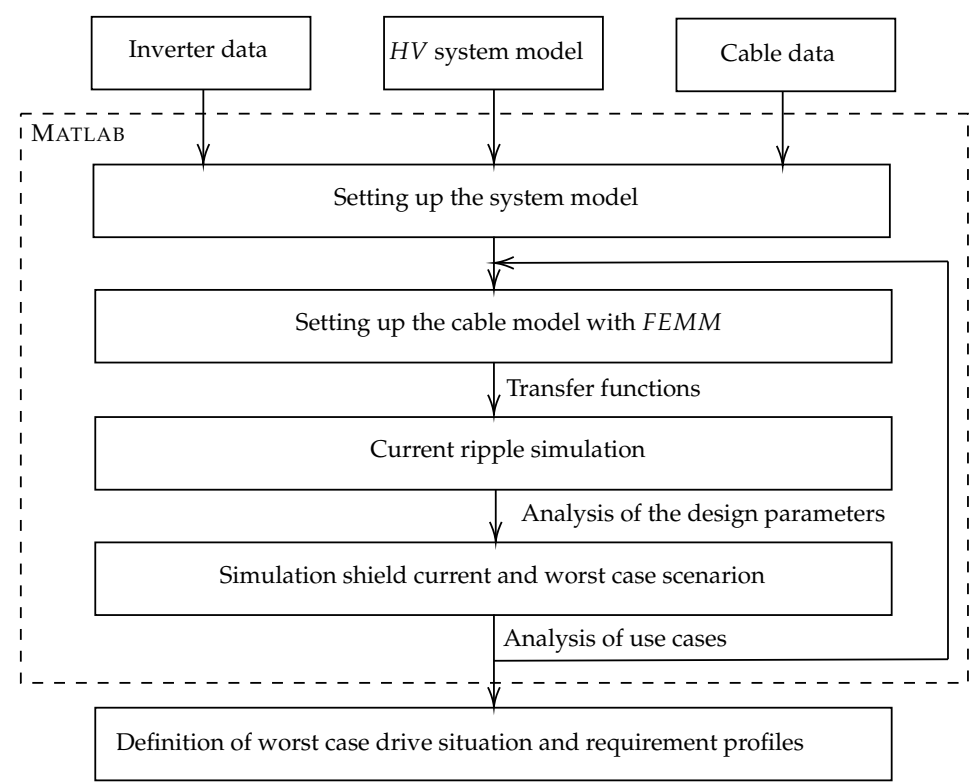

Figure 15. Derivation of the design requirement for the current stress profile of the shield grounding resistance. For this analysis, three inputs are required in the integration. Analysis can be conducted if the first inverter and the system impedance model are available. A starting point for the cabling parameters must be defined by the system developer.

\subsection{Validation}

The research questions are about unpredicted ageing phenomena and sporadic faults in real vehicle applications. We validated these by theoretical and simulation results (i.e., research related measurements). The measurement required a customised break out box that enables the measurement of the shield current and the cable core current without changing the cable length, geometry, and the system parameters. For the measurements, two Rogowski coils from the LEM company, with a maximal frequency of $200 \mathrm{kHz}$, were 
used on the interrupted shield and the cable core. Measurements were provided on a system test bench, where the measurement equipment can be assembled without any volume problem.

Regarding the measurement results shown in Figure 16, the cable core current was filtered with a band-pass filter between $[10 \mathrm{~Hz}-150 \mathrm{kHz}]$, and the shield current was filtered with the same filter parameters. In Figure 16, the measurement of a short acceleration and braking cycle of a real vehicle is presented, where the observed shield current corresponds to the predicted shield current in acceleration periods of the WLTP drive cycle, presented in Figure 13. Notably the measurements are performed with real vehicular parameters without parameter optimisation.

The measurement results revealed that in the specified frequency range the current resulting from the inductive coupling between the cable core and shield allows the measurement of shield current with an amplitude of more than $40 \%$ of the ripple current on the cable core. Moreover, the measurements showed that the 10 A RMS shield current limit can be violated during real drive situations. As a conclusion, the measurement results fulfil their validation purpose.

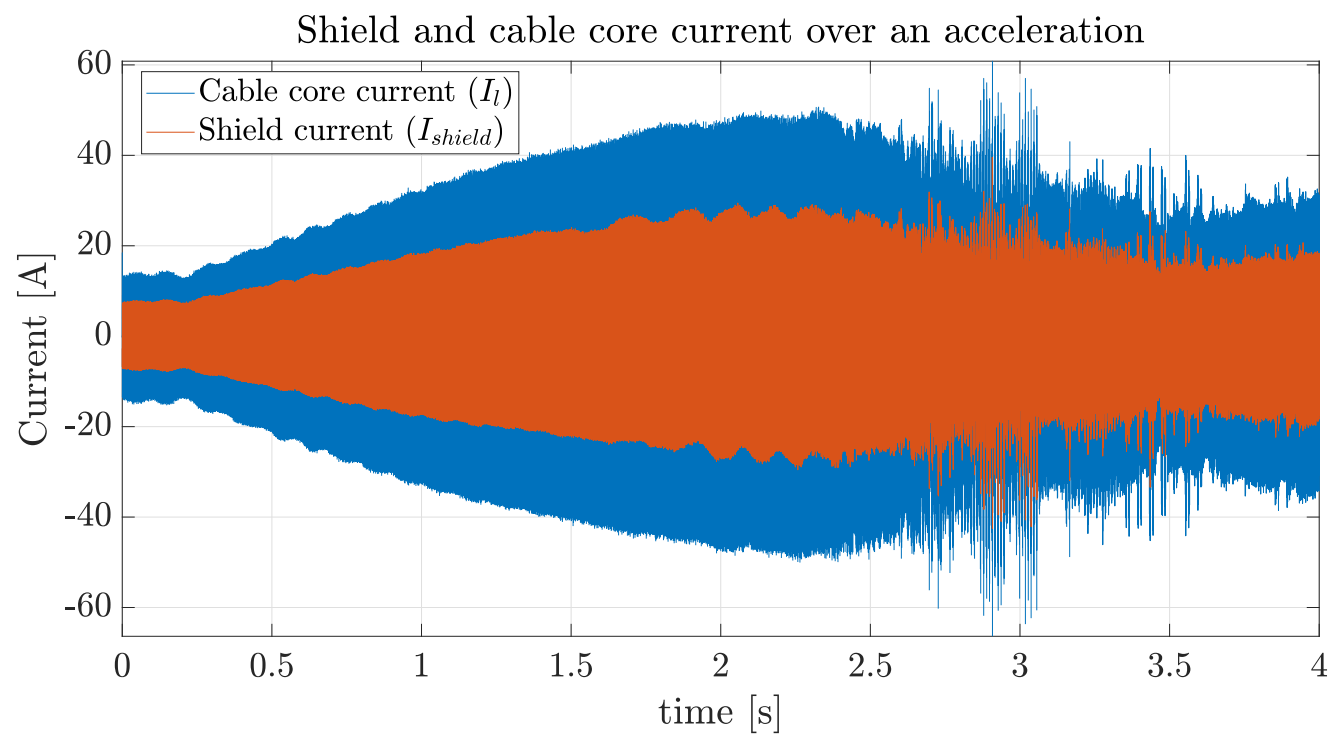

Figure 16. Measured shield and cable core current in the frequency range of $10 \mathrm{~Hz}$ to $150 \mathrm{kHz}$ in the time domain on a $50 \mathrm{~mm}^{2}$ copper cable, assembled between the HV-distributor and the front inverter, over an acceleration cycle ranging from 0 to $8000 \mathrm{rpm}$.

\section{Conclusions and Future Work}

In the presented paper, we have two main contributions to the state of the art. First, we presented an analysis of the ripple current modelling error caused by neglected individual cable shielding, with respect to the inductive coupling between cable core and shield. Second, we developed a method to set up drive-cycles and life-time shield current profiles. This method enables the redefinition of static current stress tolerance requirements on shielding and shield grounding resistors in connector systems and helps develop satisfactory drive cycles and driver behaviour, based on predicted shield currents over the life-time. The method also enables the prediction of the effect of system parameter changes on the expected shield currents. The results were validated on numeric simulations and measurements conducted in real vehicular systems. The proposed method provides a significant improvement for adding system-specific information to the design of an EV; moreover, it extends the requirement proposed in [14].

These examinations enable a better understanding of the automotive HV systems and contribute to a more robust design that facilitates the higher reliability of xEVs. In the future, it is worth extending the shield current profiles with the thermal simulation of 
the shielding and injecting possible faulty behaviours to the simulation models to enrich worst-case scenario analysis.

Author Contributions: Conceptualization, J.G.P.; Formal analysis, J.G.P.; Software, J.G.P.; Supervision, D.F. and B.B.; Validation, J.G.P.; Visualization, J.G.P.; Writing—original draft, J.G.P. All authors have read and agreed to the published version of the manuscript.

Funding: This work was supported by the TKP2020-NKA-10 project financed under the 2020-4.1.1TKP2020 Thematic Excellence Programme by the National Research, Development and Innovation Fund of Hungary. This work was supported by the UNKP-20-4 new national excellence program of the ministry for innovation and technology from the source of the national research, development and innovation fund. The program has been supported by the ZalaZONE Automotive Proving Ground Zala Ltd. The research was supported by the Ministry of Innovation and Technology NRDI Office within the framework of the Autonomous Systems National Laboratory Program.

Conflicts of Interest: The authors declare no conflict of interest.

\section{References}

1. Frei, S.; Mushtaq, A.; Hermes, K.; Nowak, R. Current distribution in shielded cable-connector systems for power transmission in electric vehicles. In Proceedings of the 2018 IEEE International Symposium on Electromagnetic Compatibility and 2018 IEEE Asia-Pacific Symposium on Electromagnetic Compatibility (EMC/APEMC), Singapore, 14-17 May 2018; pp. 881-886.

2. Karvonen, A.; Thiringer, T. Co-Simulation and Harmonic Analysis of a Hybrid Vehicle Traction System. In Proceedings of the 2015 IEEE Vehicle Power and Propulsion Conference (VPPC), Montreal, QC, Canada, 19-22 October 2015; pp. 1-6.

3. Rettner, C.; Jacob, G.; Schiedermeier, M.; Apelsmeier, A.; März, M. Voltage ripple analysis based on DC-link current harmonics for Voltage Source Inverters. In Proceedings of the 20th Workshop on Control and Modeling for Power Electronics (COMPEL), Toronto, ON, Canada, 17-20 June 2019.

4. Sagert, C.; Walter, M.; Sawodny, O.; Daimler, A.G. Modelle zur Auslegung von Zwischenkreis-Filtern in komplexen HochvoltBordnetzen. Available online: http:/ / docplayer.org/57962659-Modelle-zur-auslegung-von-zwischenkreis-filtern-in-komplexenhochvolt-bordnetzen.html (accessed on 16 October 2021).

5. Aghabali, I.; Bauman, J.; Kollmeyer, P.J.; Wang, Y.; Bilgin, B.; Emadi, A. 800-V Electric Vehicle Powertrains: Review and Analysis of Benefits, Challenges, and Future Trends. IEEE Trans. Transp. Electrif. 2021, 7, 927-948. [CrossRef]

6. Mushtaq, A.; Frei, S. Transfer impedance simulation and measurement methods to analyse shielding behaviour of HV cables used in Electric-Vehicles and Hybrid-Electric-Vehicles. Adv. Radio Sci. 2016, 14, 139-145. [CrossRef]

7. Schoerle, S.; Hoene, E.; Lang, K.D. Automotive high voltage grid simulation modelling and simulation high voltage car grids from system prospective. In Proceedings of the 2014 International Symposium on Electromagnetic Compatibility, Gothenburg, Sweden, 1-4 September 2014; pp. 426-431.

8. Mariscotti, A. Analysis of the DC link current spectrum in force commutated inverters. In Proceedings of the 1998 IEEE International Symposium on Circuits and Systems (ISCAS), Monterey, CA, USA, 31 May-3 June 1998; Volume 3, pp. $354-357$.

9. Karvonen; A; Thiringer, T. Parameter analysis of current and voltage ripple in a hybrid vehicle traction system. In Proceedings of the 2015 IEEE International Electric Machines \& Drives Conference (IEMDC), Coeur d'Alene, ID, USA, 10-13 May 2015; pp. $1838-1845$.

10. Feldhues, K.; Diebig, M.; Frei, S. Analysis of the low frequency shielding behavior of high voltage cables in electric vehicles. In Proceedings of the 2014 International Symposium on Electromagnetic Compatibility, Gothenburg, Sweden, 1-4 September 2014; pp. 408-413.

11. Tomilin, M.M. The Method of Voltage Calculation on Inner Wire of Shielded Cable Based on Transfer Function. In Proceedings of the 2020 6th Global Electromagnetic Compatibility Conference (GEMCCON), Xi'an, China, 20-23 October 2020; pp. 1-4.

12. Reuter, M.; Tenbohlen, S.; Köhler, W. The Influence of Network Impedance on Conducted Disturbances Within the High-Voltage Traction Harness of Electric Vehicles. IEEE Trans. Electromagn. Compat. 2014, 56, 35-43. [CrossRef]

13. Wen, H.; Xiao, W.; Wen, X.; Armstrong, P. Analysis and Evaluation of DC-Link Capacitors for High-Power-Density Electric Vehicle Drive Systems. IEEE Trans. Veh. Technol. 2012, 61, 2950-2964. [CrossRef]

14. Volkswagen, A.G. Electrical Characteristics and Electrical Safety of High-voltage Components in Road Vehicles: Requirements and Tests. June 2014. Available online: http:/ / www.leiditech.com/UpLoadFile/20200423/7d1d12cc-dccf-4d88-bc42-71b65fe2b3 4c.pdf (accessed on 16 October 2021).

15. Henriksson, A.; Simonsson, J.; Lundgren, U.; Ankarson, P. Cable Modeling for Accurate Estimation of Current and Voltage Ripple in Electric Vehicles. In Proceedings of the 2018 IEEE Transportation Electrification Conference and Expo (ITEC), Long Beach, CA, USA, 13-15 June 2018; pp. 714-719.

16. Murthy, M.S.; Rasek, G.A. Analytical Determination of Current Distributions in Shielded HV Cables and Ground Systems of Electric Automotive Power Trains. IEEE Trans. Electromagn. Compat. 2019, 61, 911-918. [CrossRef]

17. Di Noia, L.P.; Rizzo, R. Thermal Analysis of Battery Cables for Electric Vehicles. In Proceedings of the 2020 2nd IEEE International Conference on Industrial Electronics for Sustainable Energy Systems (IESES), Cagliari, Italy, 1-3 September 2020; pp. $298-302$. 
18. Rao, V.K. Design of High Voltage Cable for Electric Vehicle. In Proceedings of the 2019 IEEE Transportation Electrification Conference (ITEC-India), Bengaluru, India, 17-19 December 2019; pp. 1-6.

19. Schlüter, M.; Gentejohann, M.; Dieckerhoff, S. Impedance Analysis of an Automotive DC Bus. In Proceedings of the 2020 22nd European Conference on Power Electronics and Applications (EPE'20 ECCE Europe), Lyon, France, 7-11 September 2020; pp. P.1-P.10.

20. Coroplast Ltd. Technical Information Coroplast Part No.: 9-2611/50 mm². Available online: https://www.hilltop-products.co.uk/ (accessed on 15 August 2021).

21. Paul, C.R. Analysis of Multiconductor Transmission Lines; John Wiley Sons: Hoboken, NJ, USA, 2007.

22. Gustavsen, B.; Semlyen, A. Rational approximation of frequency domain responses by vector fitting. IEEE Trans. Power Deliv. 1999, 14, 1052-1061. [CrossRef]

23. Mohos, A.; Ladányi, J. Impedance characteristics of Aluminum Alloy stranded conductors in the frequency range $40 \mathrm{~Hz}$ to $150 \mathrm{kHz}$. In Proceedings of the 2017 International Symposium on Electromagnetic Compatibility-EMC EUROPE, Angers, France, 4-7 September 2017; pp. 1-4.

24. The Worldwide Harmonised Light Vehicle Test Procedure (WLTP). Available online: www.vehicle-certification-agency.gov.uk (accessed on 18 August 2021). 